\title{
CEBPG promotes acute myeloid leukemia progression by enhancing EIF4EBP1
}

You Jiang ${ }^{1 \dagger}$, Shui-Yan Wu ${ }^{1,2+}$, Yan-Ling Chen ${ }^{3,4 \dagger}, Z^{2}-M u$ Zhang ${ }^{3 \dagger}$, Yan-Fang Tao ${ }^{1,3}$, Yi Xie $^{3}$, Xin-Mei Liao $^{3}$,

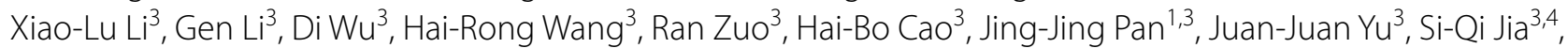
Zheng Zhang ${ }^{3}$, Xin-Ran Chu' ${ }^{1}$, Yong-Ping Zhang ${ }^{1}$, Chen-xi Feng ${ }^{3}$, Jian-Wei Wang ${ }^{3}$, Shao-Yan Hu ${ }^{1,3}$, Zhi-Heng Li ${ }^{3}$, Jian Pan ${ }^{1,3^{*}}$, Fang Fang ${ }^{3 *}$ and Jun Lu $^{1^{*}}$

\begin{abstract}
Background: Acute myeloid leukemia (AML) is a myeloid neoplasm accounts for $7.6 \%$ of hematopoietic malignancies. AML is a complex disease, and understanding its pathophysiology is contributing to the improvement in the treatment and prognosis of AML. In this study, we assessed the expression profile and molecular functions of CCAAT enhancer binding protein gamma (CEBPG), a gene implicated in myeloid differentiation and AML progression.

Methods: shRNA mediated gene interference was used to down-regulate the expression of CEBPG in AML cell lines, and knockdown efficiency was detected by RT-qPCR and western blotting. The effect of knockdown on the growth of AML cell lines was evaluated by CCK-8. Western blotting was used to detect PARP cleavage, and flow cytometry were used to determine the effect of knockdown on apoptosis of AML cells. Genes and pathways affected by knockdown of CEBPG were identified by gene expression analysis using RNA-seq. One of the genes affected by knockdown of CEBPG was Eukaryotic translation initiation factor 4E binding protein 1 (EIF4EBP1), a known repressor of translation. Knockdown of EIF4EBP1 was used to assess its potential role in AML progression downstream of CEBPG.

Results: We explored the ChIP-Seq data of AML cell lines and non-AML hematopoietic cells, and found CEBPG was activated through its distal enhancer in AML cell lines. Using the public transcriptomic dataset, the Cancer Cell Line Encyclopedia (CCLE) and western blotting, we also found CEBPG was overexpressed in AML. Moreover, we observed that CEBPG promotes AML cell proliferation by activating EIFAEBP1, thus contributing to the progression of AML. These findings indicate that CEBPG could act as a potential therapeutic target for AML patients.

Conclusion: In summary, we systematically explored the molecular characteristics of CEBPG in AML and identified CEBPG as a potential therapeutic target for AML patients. Our findings provide novel insights into the pathophysiology of $A M L$ and indicate a key role for CEBPG in promoting AML progression.
\end{abstract}

Keywords: CEBPG, EIF4EBP1, Acute myeloid leukemia, Proliferation, Apoptosis

*Correspondence: panjian2008@163.com; fangf@suda.edu.cn; drlujun_sz@163.com

†You Jiang, Shui-Yan Wu, Yan-Ling Chen, and Zi-Mu Zhang contributed equally to this work

${ }^{1}$ Department of Hematology, Children's Hospital of Soochow University, No.92 Zhongnan Street, SIP, Suzhou 215003, Jiangsu, China

${ }^{3}$ Institute of Pediatric Research, Children's Hospital of Soochow University, No.92 Zhongnan Street, SIP, Suzhou 215003, China

Full list of author information is available at the end of the article

\section{Introduction}

Acute myeloid leukemia (AML) is a myeloid neoplasm that accounts for $7.6 \%$ of hematopoietic malignancies. It is caused by the oncogenic transformation of hematopoietic progenitors in the bone marrow (BM), which results in the destruction of blood tissue. AML is reported to have a long-term survival of less than $20 \%$ [1-3]. Every year there are about 18,000 new cases AML in Europe

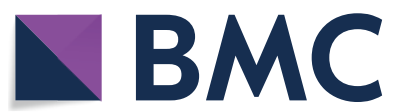

(c) The Author(s) 2021. Open Access This article is licensed under a Creative Commons Attribution 4.0 International License, which permits use, sharing, adaptation, distribution and reproduction in any medium or format, as long as you give appropriate credit to the original author(s) and the source, provide a link to the Creative Commons licence, and indicate if changes were made. The images or other third party material in this article are included in the article's Creative Commons licence, unless indicated otherwise in a credit line to the material. If material is not included in the article's Creative Commons licence and your intended use is not permitted by statutory regulation or exceeds the permitted use, you will need to obtain permission directly from the copyright holder. To view a copy of this licence, visit http://creativecommons.org/licenses/by/4.0/. The Creative Commons Public Domain Dedication waiver (http://creativecommons.org/publicdomain/zero/1.0/) applies to the data made available in this article, unless otherwise stated in a credit line to the data. 
[4]. AML is a complex disease, and understanding its pathophysiology will contribute to improving the treatment and prognosis of AML [5-8].

CCAAT enhancer binding proteins (CEBPs) including CEBPA, CEBPB, CEBPD, CEBPE, CEBPG and CEBPZ, are suggested as potential biomarkers for cancer prognosis [9-14]. CEBPB plays a role in gastric cancer progression [15], and is involved in breast cancer cell migration and invasion [16]. Both CEBPB and CEBPD function in cancer cell survival [17]. CEBPD is also reported to participate in papillary thyroid carcinoma progression [18]. CEBPE is suggested as a prognostic factor for AML [19], and CEBPZ is also reported to be mutated in AML [20].

Among CEBPs, CEBPA, CEBPE and CEBPZ have been reported to function in AML development $[9,19,20]$, however the role of CCAAT enhancer binding protein gamma (CEBPG) in AML is unclear. CEBPG is a member of leucine-zipper transcription factor family that plays a role in many biological processes [21-24]. Knockdown of $C E B P G$ suppressed tumor growth [25]. CEBPG is suggested as a biomarker for lung cancer risk [26]. It is also involved in the differentiation arrest in AML $[27,28]$. Although the roles of $C E B P G$ in several types of cancer have been revealed, its expression profile and molecular functions in AML remain unresolved. Therefore, in this study we assess the role of CEBPG in AML progression.

In the present study, shRNA mediated gene interference was used to down-regulate the expression of CEBPG in AML cell lines, and the knockdown efficiency was detected by RT-qPCR and western blotting. The effect of $C E B P G$ knockdown on the growth of AML cell lines was evaluated by Cell Counting Kit- 8 (CCK-8) assays. Western blotting was used to detect poly(ADPribose) polymerase (PARP) cleavage, and flow cytometry was used to determine the effect of CEBPG knockdown on apoptosis of AML cells. Genes and pathways affected by knockdown of $C E B P G$ were identified by gene expression analysis using RNA-seq.

One of the genes affected by knockdown of $C E B P G$ was Eukaryotic translation initiation factor $4 \mathrm{E}$ binding protein 1 (EIF4EBP1). EIF4EBP1 is a translation repressor protein [29] that plays a role in multiple types of cancer, including lung, breast, and liver cancer [30-33]. For example, EIF4EBP1 is reported to be significantly overexpressed in hepatocellular carcinoma (HCC) tissues and is related to poor survival of patients with HCC [33]. However, the biological effect and underlying mechanism of EIF4EBP1 in AML has not been explored. Therefore, knockdown of EIF4EBP1 was used to assess its potential role in AML progression downstream of CEBPG.

In the present study, we explored the ChIP-Seq data of AML cell lines and non-AML hematopoietic cells and found $C E B P G$ was activated through its distal enhancer in AML cell lines. Using the public transcriptomic dataset, the Cancer Cell Line Encyclopedia (CCLE) and western blotting, we also found that $C E B P G$ was overexpressed in AML. Moreover, CEBPG promotes AML cell proliferation by activating EIF4EBP1, thus contributing to the progression of AML. These findings indicate that $C E B P G$ could act as a potential therapeutic target for AML patients.

\section{Materials and methods \\ Cell lines and culture}

Human AML cell lines, including NB4,THP-1, MV4-11, and $\mathrm{K} 562$ which was from blastic crisis of chronic myelogenous leukemia were obtained from the cell bank of the American type culture collection and cultured in RPMI medium (Termo Fisher Scientifc) containing 10\% fetal bovine serum (Biological Industries, CT, USA), and $1 \%$ penicillin-streptomycin (Beyotime Biotechnology, Shanghai, China) at $37^{\circ} \mathrm{C}$ in a humidified incubator with an atmosphere of $5 \% \mathrm{CO} 2$ and tested routinely for mycoplasma.

\section{Lentivirus preparation and infection}

Short hairpin RNA (shRNA) targeting CEBPG and EIF$4 E B P 1$ (Table 1) were constructed in the pLKO.1-puro lentiviral vector (IGE BIOTECHNOLOGY LTD, Guangzhou, China). For lentivirus preparation, the envelope plasmid and packaging plasmid were purchased from Addgene (pMD2.G: \#12,259; psPAX2:\#12,260; Cambridge, MA, USA). pMD2.G, psPAX2 and the transfer plasmid were cotransfected into 293FT cells using polyethylenimine (linear MW 25,000 Da, $5 \mathrm{mg} / \mathrm{mL}, \mathrm{pH} 7.0$ ) (cat. No. 23966-1; Polysciences, Warrington, PA, USA) according to the manufacturer's instructions. After $6 \mathrm{~h}$, the culture medium was completely replaced with fresh

Table 1 shRNAs used to knockdown CEBPG and EIF4EBP1

\begin{tabular}{ll}
\hline Name & Sequence \\
\hline Homo-CEBPG -sh1 & CCGGGATTTGTTTCTTGAGCATGCACTCGAG \\
& TGCATGCTCAAGAAACAAATCTTTTTGAATT \\
Homo-CEBPG -sh2 & CCGGTGGCGACAATGCAGGACAGTACTCGA \\
& GTACTGTCCTGCATTGTCGCCATTTTTGAATT \\
Homo-CEBPG -sh3 & CCGGGCAACGCCGAGAGAGGAACAACTCGA \\
& GTTGTCCTCTCTCGGCGTTGCTTTTTGAATT \\
Homo-EIF4EBP1-sh1 & CCGGGCCAGAGCCACCTGCGCAATACTCGA \\
Homo-EIF4EBP1-sh2 & GTATTGCGCAGGTGGCTCTGGCTTTTTGAATT \\
& GGCTTATCTTCTGGGCTATTGCTTTTTGAATT \\
Homo-EIF4EBP1-sh3 & CCGGGCGGTGAAGAGTCACAGTTTGCTCGA \\
& GCAAACTGTGACTCTTCACCGCTTTTTGAATT
\end{tabular}




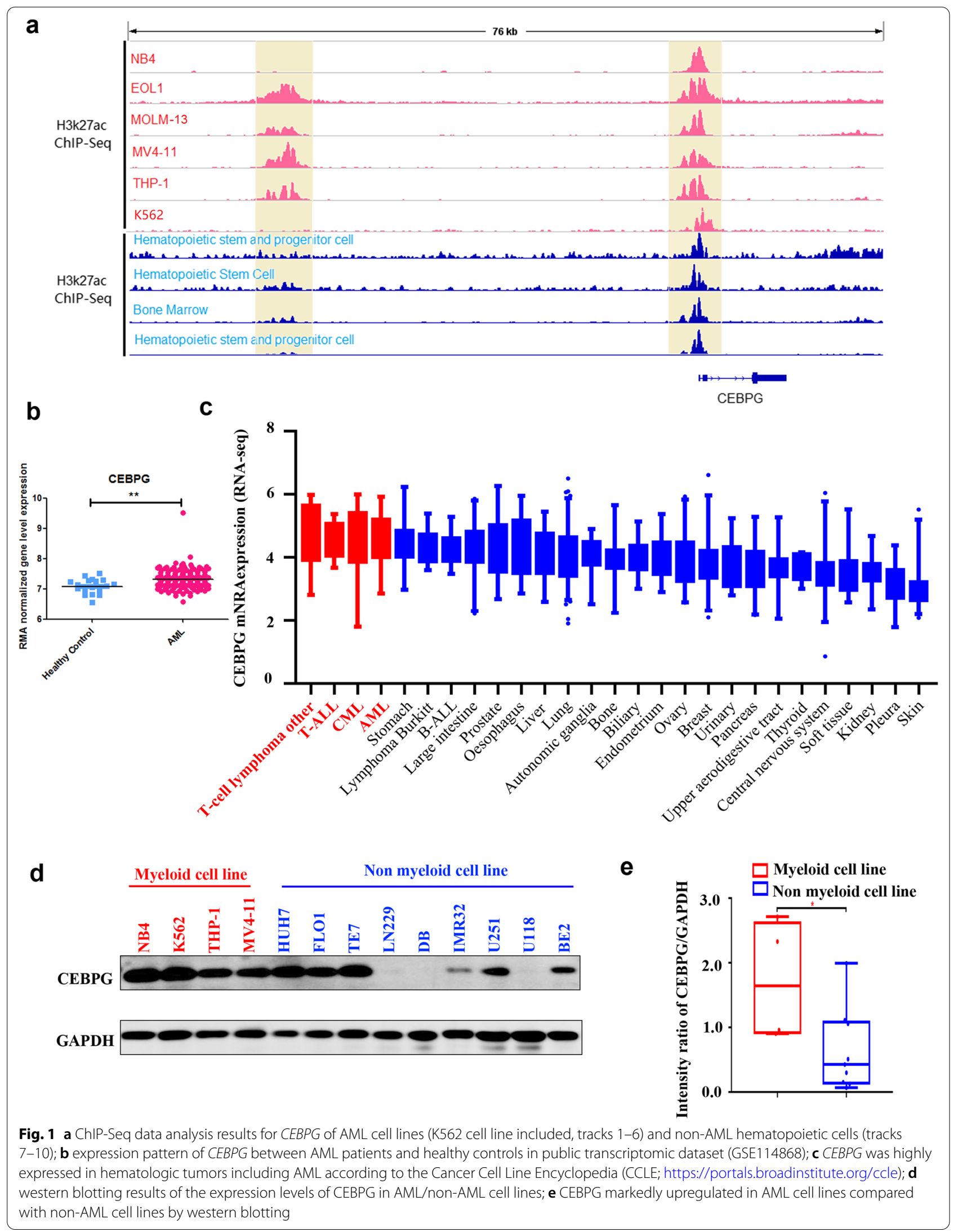


Table 2 Primers used for qRT-PCR analyses

\begin{tabular}{ll}
\hline Name & Sequence $\left(\mathbf{5}^{\prime}\right.$ - ( $^{\prime}$ ) \\
\hline CEBPG Forward & GAAAAAGAGCCGGTTGAAAGC \\
CEBPG Reverse & ACTGTACGTTGTCTGCAAGGT \\
EIF4EBP1 Forward & CTATGACCGGAAATTCCTGATGG \\
EIF4EBP1 Reverse & CCCGCTTATCTTCTGGGCTA \\
GAPDH Forward & TGCACCACCAACTGCTTAG \\
GAPDH Reverse & GATGCAGGGATGATGTTC \\
PDGFB Forward & CTCGATCCGCTCCTTTGATGA \\
PDGFB Reverse & CGTTGGTGGGTCTATGAG \\
SRC Forward & TGGCAAGATCACCAGACGG \\
SRC Reverse & GGCACCTTTCGTGGTCTCAC \\
PLCG1 Forward & GGAAGACCTCACGGGACTTTG \\
PLCG1 Reverse & GCGTTTTCAGGCGAAATTCCA \\
EIF4E Forward & ATGTGGCGCTGTTGTAATGT \\
EIF4E Reverse & CTGCGTGGGACTGATAACCAA \\
AXL Forward & GTGGGCAACCAGGGAATATC \\
AXL Reverse & GTACTGTCCCGTGTCGGAAAG \\
PIK3R2 Forward & TCACCTTCTGCTCCGTTGTG \\
PIK3R2 Reverse & GGAGGTCCGTGTGTACTCTTC \\
MET Forward & AGCGTCAACAGAGGGACCT \\
MET Reverse & GCAGTGAACCTCCGACTGTATG \\
\hline
\end{tabular}

medium. The viral supernatant was harvested at $48 \mathrm{~h}$ post-transfection and filtered through a $0.22 \mu \mathrm{m}$ filter. The leukemia cells were then infected with lentivirus in the presence of $10 \mu \mathrm{g} / \mathrm{mL}$ Polybrene (Sigma-Aldrich) for $24 \mathrm{~h}$. Stable cell lines were selected with puromycin (Sigma-Aldrich).

\section{Cell viability assay}

Leukemia cells were seeded in 96-well plates at a density of $1 \times 10^{3}$ cells per well. The cell viability was determined by Cell Counting kit-8 (CCK8) assay (Dojindo Molecular Technologies, Tokyo, Japan) according to the manufacturer's instructions. Cell proliferation was calculated as a percentage of that in cells in control medium. Each concentration was tested in triplicate and repeated in at least three independent experiments. The calculation was performed by Graph Prism software 7.0 (GraphPad Software Inc., San Diego, CA, USA).
RNA preparation and real-time PCR expression analysis Total RNA was extracted from cell pellets using TRIzol ${ }^{\circledR}$ reagent (Invitrogen, CA, USA), according to the manufacturer's protocol. For cDNA synthesis, $1 \mu \mathrm{g}$ of total RNA was converted to cDNA using a High-Capacity cDNA Reverse Transcription Kit (Applied Biosystems, CA, USA). Quantitative real-time PCR analysis was carried out using LightCycler ${ }^{\circledR} 480$ SYBR Green I Master mix (cat. No. 04707516001; Roche, Penzberg, Germany) with a LightCycler 480 Real Time System (Roche), according to the manufacturer's protocol. mRNA expression levels were calculated using the $\mathrm{Ct}$ method with glyceraldehyde 3-phosphate dehydrogenase (GAPDH) expression as an internal reference. Primer sequences are listed in Table 2.

\section{Western blotting analysis}

Western blotting analysis was conducted using the following primary antibodies: CEBPG (cat. sc-517003; 1:500; Santa Cruz Biotechnology, Inc. Dallas, Texas,USA), EIF4EBP1 (cat. \#9644,1:1000; Cell Signaling Technology, Boston, MA, USA), and PARP (cat. No. 9542; 1:1000; Cell Signaling Technology), with glyceraldehyde 3-phosphate dehydrogenase (GAPDH) (cat. No. MA3374; 1:1000; Millipore) as a reference protein. Peroxidase-conjugated Afniure goat anti-rabbit IgG $(\mathrm{H}+\mathrm{L})$ (cat.111-035-003; 1:5000) and goat anti-mouse IgG $(\mathrm{H}+\mathrm{L})$ (cat. No. 115035-003; 1:5000) secondary antibodies were purchased from Jackson ImmunoResearch Laboratories, Inc. (West Grove, PA, USA). ImageJ software was used for band quantifcation. Then, protein levels were determined using a GAPDH antibody for normalization.

\section{Cell apoptosis assay}

Leukemia cells (MV4-11, NB4, and K562 cell lines) were infected with lentivirus in the presence of $10 \mu \mathrm{g} /$ $\mathrm{mL}$ Polybrene (Sigma-Aldrich) for $24 \mathrm{~h}$. Stable cell lines were selected with puromycin (Sigma-Aldrich). Following 4 days incubation, leukemia cells were harvested and washed with cold PBS, suspended in $1 \times$ binding bufer, and stained with fuorescein isothiocyanate (FITC)-Annexin V antibody and PI solution using an FITC-Annexin V apoptosis kit (cat. No.556420; BD

\footnotetext{
(See figure on next page.)

Fig. 2 a Knockdown efficiency of CEBPG was evaluated in THP-1 cell line by western blotting. b Knockdown efficiency of CEBPG was evaluated in THP-1 cell line by qPCR. c Knockdown of CEBPG significantly inhibited the proliferation rates of THP-1 cell line. $\mathbf{d}$ Knockdown of CEBPG significantly inhibited the proliferation rates of THP-1 cell line. e Knockdown efficiency of CEBPG was evaluated in MV4-11, THP-1, and NB4 cell lines by western blotting. $\mathbf{f}$ Knockdown efficiency of CEBPG was evaluated in MV4-11, THP-1, and NB4 cell lines by qPCR. g Knockdown of CEBPG significantly inhibited the proliferation rates of MV4-11 and NB4 cell lines. $\mathbf{h}$ Knockdown of CEBPG significantly inhibited the proliferation rates of MV4-11, THP-1, and NB4 cell lines. i PARP was increased in both MV4-11 and NB4 cell lines upon knockdown of CEBPG. j Flow cytometry showed that knockdown of CEBPG increased the apoptotic rates of MV4-11 and NB4 cell lines. k Knockdown of CEBPG increased the apoptotic rates of MV4-11 and NB4 cell lines
} 
Biosciences, Franklin Lakes, NJ, USA), according to the manufacturer's instructions. Cell apoptosis was analyzed by flow cytometry (Beckman Gallios ${ }^{\mathrm{TM}}$ Flow Cytometer; Beckman).

\section{RNA-seq and data processing}

RNA-seq was carried out according to the protocols suggested by Novogene, Beijing, China. First, total RNA was reverse transcribed to cDNA for library construction, and the cDNA library was then sequenced. The raw reads were filtered and clean reads were mapped according to HISAT. The gene expression level (as fragments per kilobase of exon model per million reads mapped) was then calculated. Differentially expressed genes $(\mathrm{P}<0.05$ and fold-change $>2$ or fold-change $<0.5$ ) were identified using DESeq2 analysis. For enrichment analysis, differentially expressed genes were analyzed using the DAVID Bioinformatics Resources v6.8 online server (https://david. ncifcrf.gov).

\section{Chromatin immunoprecipitation (ChIP)}

$3-5 \times 10^{7}$ cells were crosslinked with $1 \%$ formaldehyde for $10 \mathrm{~min}$ and neutralized with $1.25 \mathrm{M}$ glycine for $5 \mathrm{~min}$ at room temperature. Fixed cells were harvested, lysed, and sonicated using a Bioruptor (Diagenode, Liège, Belgium). Sonicated chromatin was incubated with anti-histone H3 (acetyl K27) antibody (cat. No. ab4729; Abcam, Cambridge, UK) overnight at $4{ }^{\circ} \mathrm{C}$. DNA was eluted and purified using a QIAquick PCR purification kit (cat. No. 208106; Qiagen, Hilden, Germany). Samples were sequenced on a novaseq 6000 platform (Novogene Bioinformatics Technology Co., Ltd. Beijing, China). Raw data of ChIP-Seq H3K27ac analysis for NB4 cell line was aligned to the reference genome (UCSC hg38) using Bowtie2 (v 2.3.5) [34], with alignment parameters -p 4 -q -x. Peaks were identified using MACS2 (v2.0.9) [35], with parameters $-\mathrm{g}$ hs $-\mathrm{n}$ test $-\mathrm{B}-\mathrm{q} 0.01$. The bedgraph files generated by MACS2 were converted to bigwig files using the UCSC bedGraphToBigWig tool, and then bigwig files were visualized by Integrative Genomics Viewer (IGV) [36].

\section{Public ChIP-Seq data collection and analysis}

In this study, we searched public ChIP-Seq H3K27ac datasets of AML cell lines and non-AML hematopoietic cells in the Cistrome database (http://www.cistr ome.org/). The ChIP-Seq datasets of H3K27ac and CEBPG in K562 cell line were also obtained in the Cistrome database. The bigwig files of those datasets obtained (GSE113040, GSE80779, GSE76783, GSE79899, GSE71809, GSE107147, GSE70660, GSE93372,
GSE105532, GSE70482) were further visualized by Integrative Genomics Viewer (IGV) [36].

\section{Statistical analysis}

The association between EIF4EBP1 expression and overall survival of AML patients were assessed using the Kaplan-Meier analysis. Comparison between two groups was carried out using the Student's t-test or the MannWhitney u test. Statistical analysis was carried out by GraphPad Prism 7.0 (GraphPad Software, Inc., La Jolla, CA, USA). Statistically significant $P$ values are indicated as ${ }^{*} \mathrm{P}<0.05,{ }^{* * *} \mathrm{P}<0.01,{ }^{* * * *} \mathrm{P}<0.001$, and ${ }^{* * * * *} \mathrm{P}<0.0001$.

\section{Results}

CEBPG is activated through its distal enhancer and is overexpressed in AML cell lines

By interrogating ChIP-Seq data of AML cell lines (Fig, 1a, tracks 1-6, K562 cell line also included) and non-AML hematopoietic cells (Fig. 1a, tracks 7-10), we found that the enhancer region of $C E B P G$ in AML cell lines showed coincident H3K27ac signals that were not present in non-AML hematopoietic cells, suggesting a potential role in transcription regulation. Then, we assessed the expression pattern of CEBPG between AML patients and healthy controls in a public transcriptomic dataset (GSE114868) [37], and found that CEBPG was more highly expressed in AML samples (Fig. 1b) relative to that in healthy control samples (the differentially expressed genes between AML and control samples in dataset GSE114868 are listed in Additional file 1: Table S1). Moreover, the Cancer Cell Line Encyclopedia (CCLE; https://portals.broadinstitute.org/ccle) which includes CEBPG mRNA expression profiles for multiple cancer cell lines, showed that CEBPG was highly expressed in hematologic malignancies including AML (Fig. 1c). We also assessed the levels of CEBPG in AML and non-AML cell lines using western blotting, and found higher levels of CEBPG in AML cell lines than in non-AML cell lines (Fig. 1d and e). Collectively, these data suggested that $C E B P G$ is activated through its distal enhancer and overexpressed in AML.

\section{CEBPG is oncogenic and promotes AML cell proliferation}

To address the biological significance of $C E B P G$, we selected three AML cell lines with high CEBPG protein levels shown in Fig. 1d (THP-1, NB4 and MV4-11) and performed shRNA-mediated knockdown of CEBPG using three independent shRNAs (Table 1). Knockdown efficiency of CEBPG was evaluated using western blotting and qPCR (Fig. 2a, b, e and f). Notably, knockdown of $C E B P G$ significantly inhibited the proliferation rates of all 3 AML cell lines (Fig. 2c, d, g and h). We also assessed the level of the apoptotic protein PARP using western 


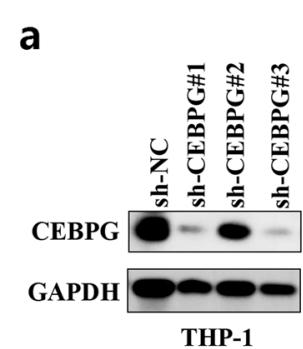

d

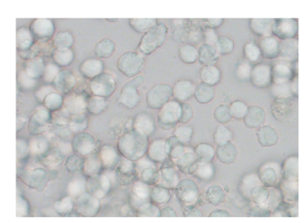

sh-NC b

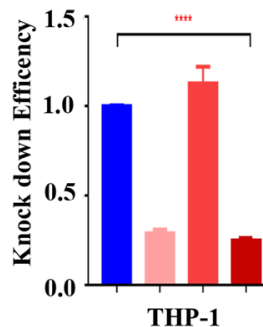

C

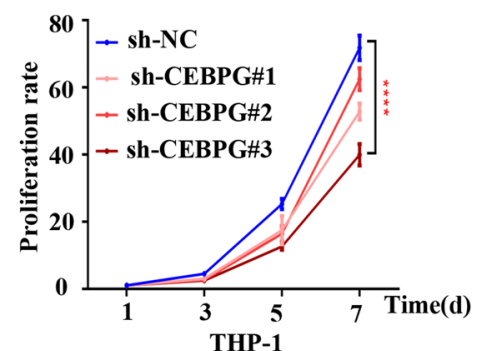

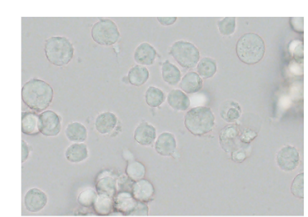

sh-CEBPG\#1
- sh-NC

sh-CEBPG\#1

sh-CEBPG\#2

- sh-CEBPG\#3
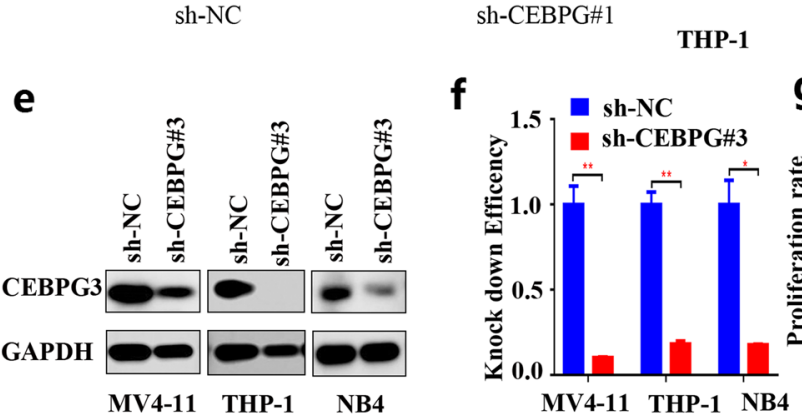

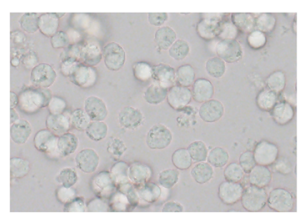

sh-CEBPG\#2

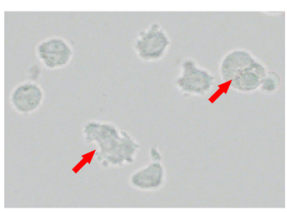

sh-CEBPG\#3

\section{g}
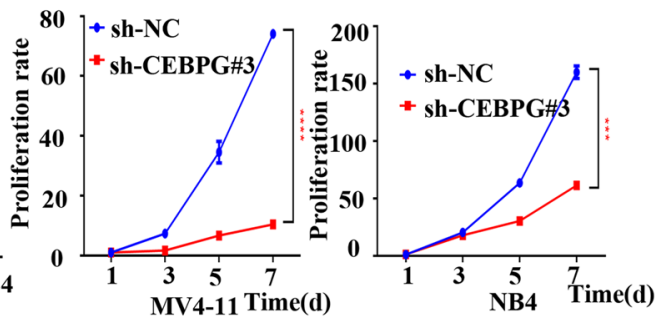

h
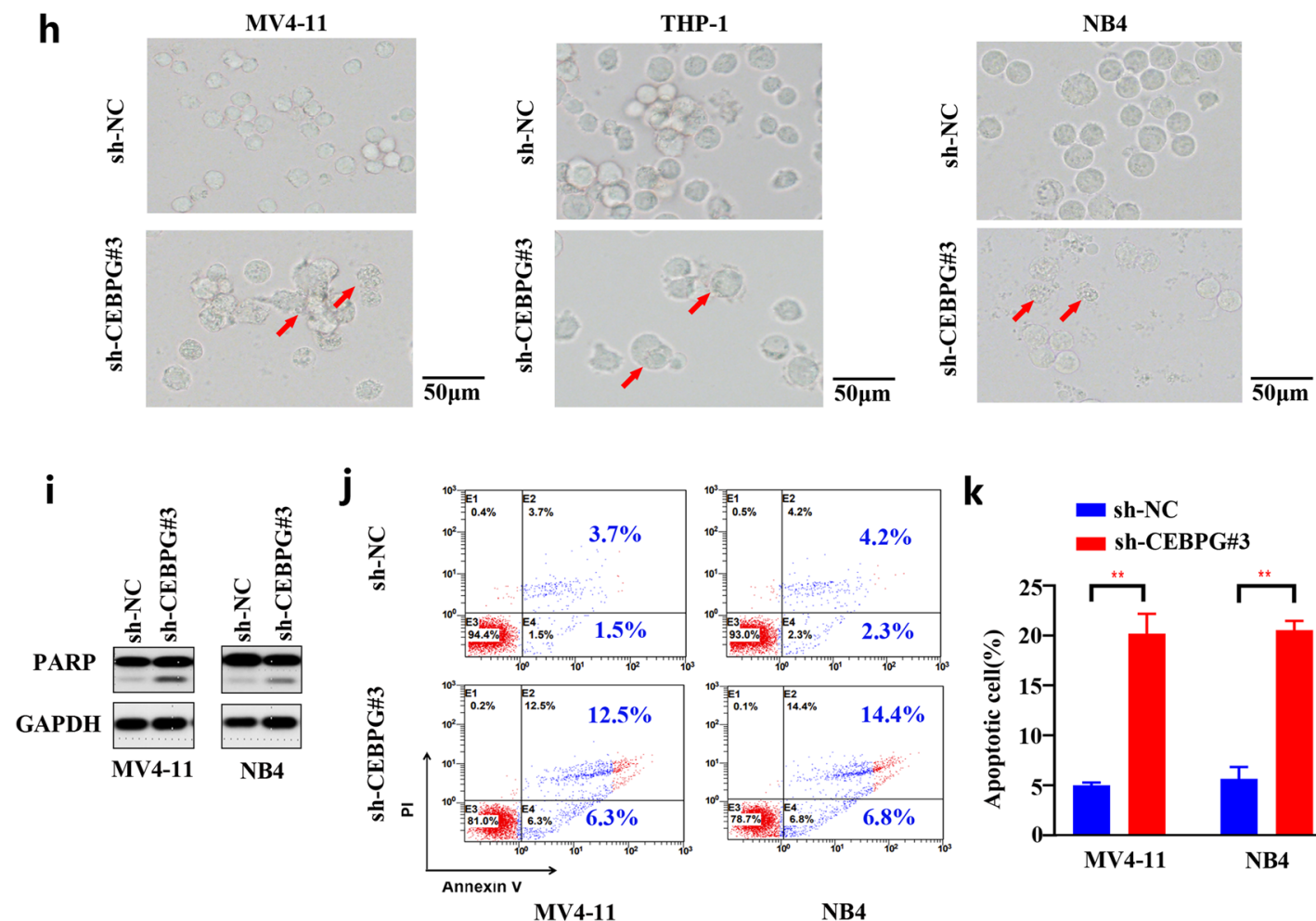

k
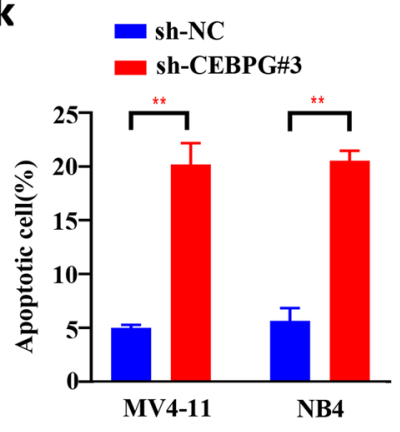

Fig. 2 (See legend on previous page.) 
blotting and found that PARP levels were increased in both MV4-11 and NB4 cell lines upon knockdown of $C E B P G$ (Fig. 2i). Knockdown of CEBPG also increased the apoptotic rates of MV4-11 and NB4 cell lines (Fig. 2j and k). Altogether, these data suggested that CEBPG is oncogenic and contributes to the proliferation of AML cells.

\section{CEBPG activates EIF4EBP1 in AML cell lines}

To reveal potential targets responsible for CEBPG-promoted AML cell proliferation, RNA-seq analyses were performed on NB4 and MV4-11 cell lines comparing shRNA control cells with CEBPG knockdown cells. A total of 1196 and 2207 differently expressed genes (DEGs) were identified upon CEBPG knockdown, in NB4 and MV4-11 cell lines respectively (Log2 |fold change $\mid>1$, $\mathrm{P}<0.05$, Fig. 3a and b). EIF4EBP1 was included in the top 10 downregulated genes upon CEBPG knockdown in both NB4 and MV4-11 cell lines (Fig. 3c and d). Next, we conducted a functional enrichment analysis of all DEGs using the KEGG Pathway Database. The results showed a significant enrichment for EGFR tyrosine kinase inhibitor resistance signaling (ranking $4^{\text {th }}$ ), which involves EIF4EBP1 (Fig. 3e). Therefore, EIF4EBP1 was selected for in-depth investigation. To further determine the regulation of CEBPG on EGFR tyrosine kinase inhibitor resistance signaling and EIF4EBP1, a total of 8 genes (EIF4EBP1, PLCG1, EIF4E, AXL, PIK3R2, MET, PDGFB and $S R C$ ) from the EGFR tyrosine kinase inhibitor resistance signaling pathway was selected for qRT-PCR validation. In accordance with the RNA-Seq results, the mRNA levels of 6 of these genes, including EIF4EBP1, were downregulated while 2 genes were upregulated in NB4 cells in response to CEBPG silencing (Fig. $3 \mathrm{f}$ and g). Additionally, ChIP-Seq data of AML cell lines and K562 cell line showed that the promoter region of EIF4EBP1 had coincident H3K27ac signals (Fig. 3h, tracks 1-6), while the ChIP-Seq data from K562 cells further indicated that EIF4EBP1 was bound by CEBPG at its TSSproximal regions (Fig. $3 \mathrm{~h}$, track 7 ), suggesting a potential role for CEBPG in the transcriptional regulation of EIF$4 E B P 1$. Therefore, we next investigated the role of EIF$4 E B P 1$ in NB4 and K562 cells.
EIF4EBP1 knockdown interferes with AML cell proliferation and increases apoptosis

To evaluate the biological significance of EIF4EBP1, we selected 2 cell lines (NB4 and K562) and knocked down EIF4EBP1 in both cell lines using three independent shRNAs (Table 1). Knockdown efficiency of EIF4EBP1 was evaluated using western blotting and qPCR (Fig. 4a, $\mathrm{b}, \mathrm{h}$ and i). Notably, knockdown of EIF4EBP1 significantly inhibited the proliferation rates of both cell lines (Fig. 4c, d, j and k). We also assessed the expression level of the apoptotic protein PARP using western blotting and found that PARP levels increased in both NB4 and K562 cell lines upon knockdown of EIF4EBP1 (Fig. 4e and l). Knockdown of EIF4EBP1 also increased the apoptotic rates of NB4 and K562 cell lines (Fig. 2f, g, 4m and n). Collectively, these data suggested that EIF4EBP1 is required to sustain proliferation and survival of AML cells.

\section{Identification of EIF4EBP1 as an unfavorable prognostic factor for AML patients}

We assessed the expression pattern of EIF4EBP1 between AML patients and healthy controls in two public transcriptomic datasets (GSE114868 and GSE142700) [37]. The results showed that EIF4EBP1 was significantly overexpressed in AML samples in both datasets (Fig. 5a and b). To further explore the prognostic value of EIF4EBP1, we used the online tool http://gepia.cancer-pku.cn/ and the result showed that the overall survival of AML patients with higher EIF4EBP1 expression was significantly poorer than those with lower EIF4EBP1 expression (Fig. 5c). These results suggested that EIF4EBP1 represents a negative prognostic factor for AML patients.

\section{Discussion}

AML is an aggressive malignancy with poor prognosis [8]. It is a complex disease and a detailed understanding of its pathophysiology is required to improve the treatment and prognosis of AML [5-8].

CCAAT enhancer binding proteins (CEBPs) including CEBPA, CEBPB, CEBPD, CEBPE, CEBPG and CEBPZ, are suggested as potential biomarkers for cancer prognosis [9-14]. Among CEBPs, CCAAT enhancer binding protein gamma (CEBPG), a member of leucine-zipper

\footnotetext{
(See figure on next page.)

Fig. 3 a Volcano Plot of RNA-seq results for NB4 cell line in either the absence or presence of CEBPG. $\mathbf{b}$ Volcano Plot of RNA-seq results for MV4-11 cell line in either the absence or presence of CEBPG. c Top 10 downregulated and top 10 upregulated genes upon CEBPG knockdown in NB4 cell line. $\mathbf{d}$ Top 10 downregulated and top 10 upregulated genes upon CEBPG knockdown in MV4-11 cell line. e Enrichment analysis results of all DEGs by using the KEGG Pathway Database. f qRT-PCR results of 6 genes (EIF4EBP1, PLCG1, EIF4E, AXL, PIK3R2 and MET) from EGFR tyrosine kinase inhibitor resistance signaling pathway in NB4 cell line when silencing CEBPG. $\mathbf{g}$ qRT-PCR results of 2 genes (PDGFB and SRC) from EGFR tyrosine kinase inhibitor resistance signaling pathway in NB4 cell line when silencing CEBPG. $\mathbf{h}$ ChIP-Seq data of AML cell lines and K562 cell line showed that the promoter region of EIF4EBP1 had coincident H3K27ac signals (tracks 1-6), ChIP-Seq data of K562 cell line further indicated that EIF4EBP1 was bound by CEBPG at its TSS-proximal regions (track 7)
} 


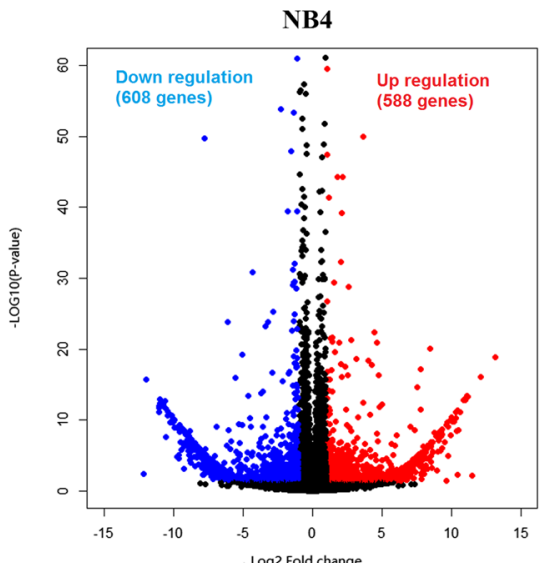

b

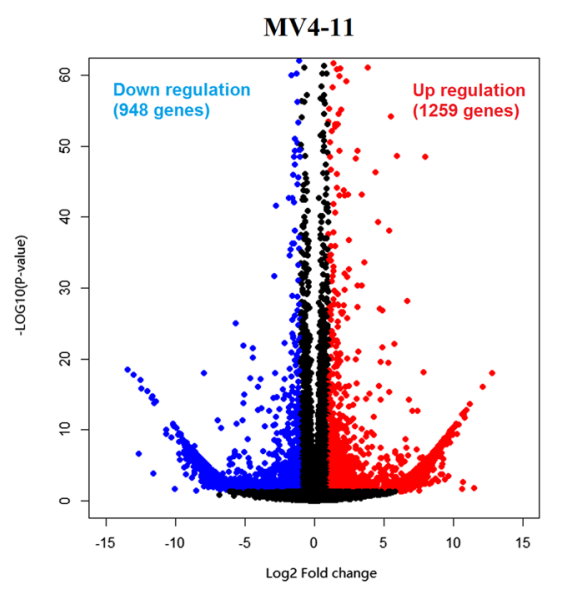

C sh-NC sh-CEBPG\#3

e

d h-NC sh-CEBPG\#3

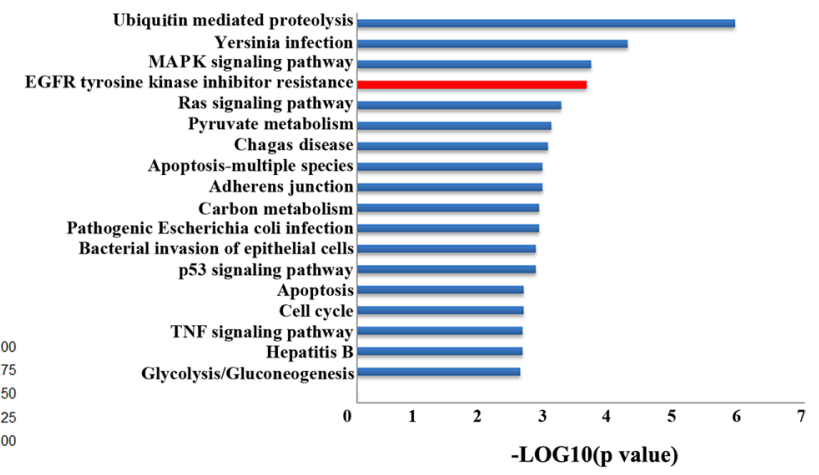

g f

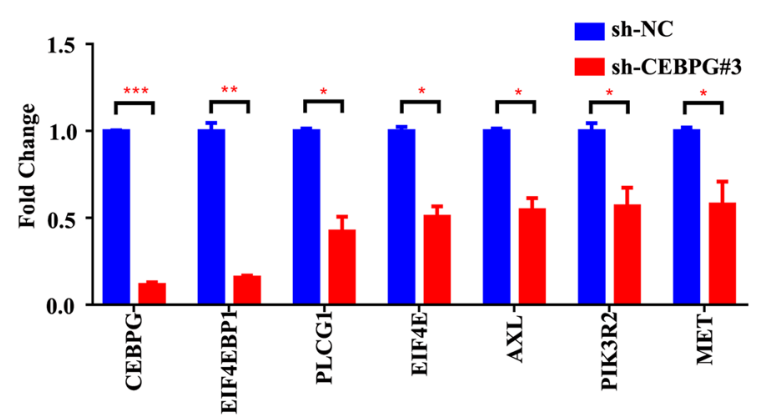

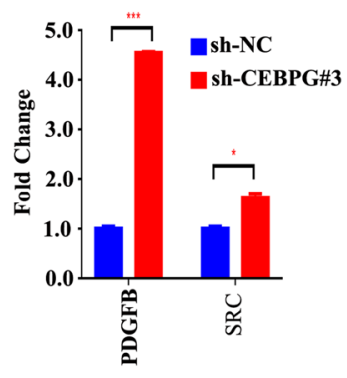

h

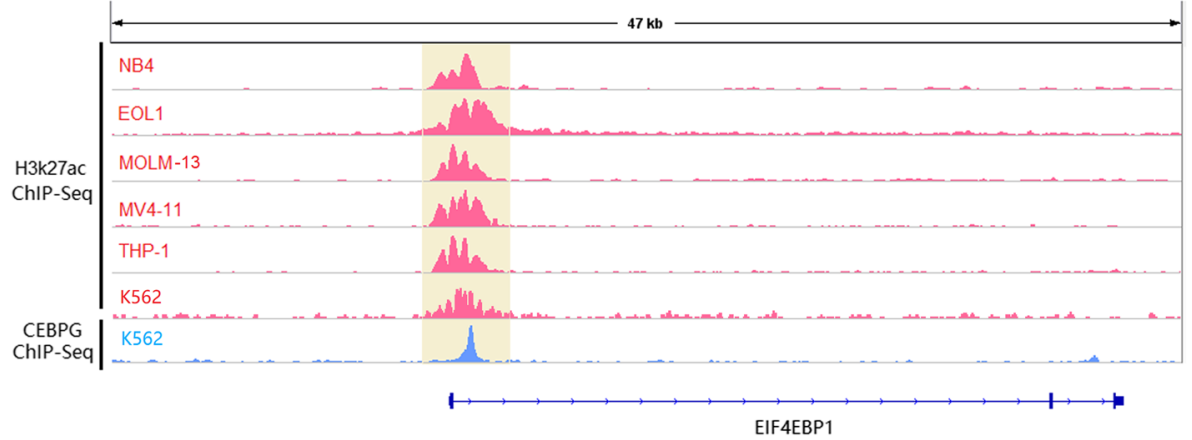

Fig. 3 (See legend on previous page.) 


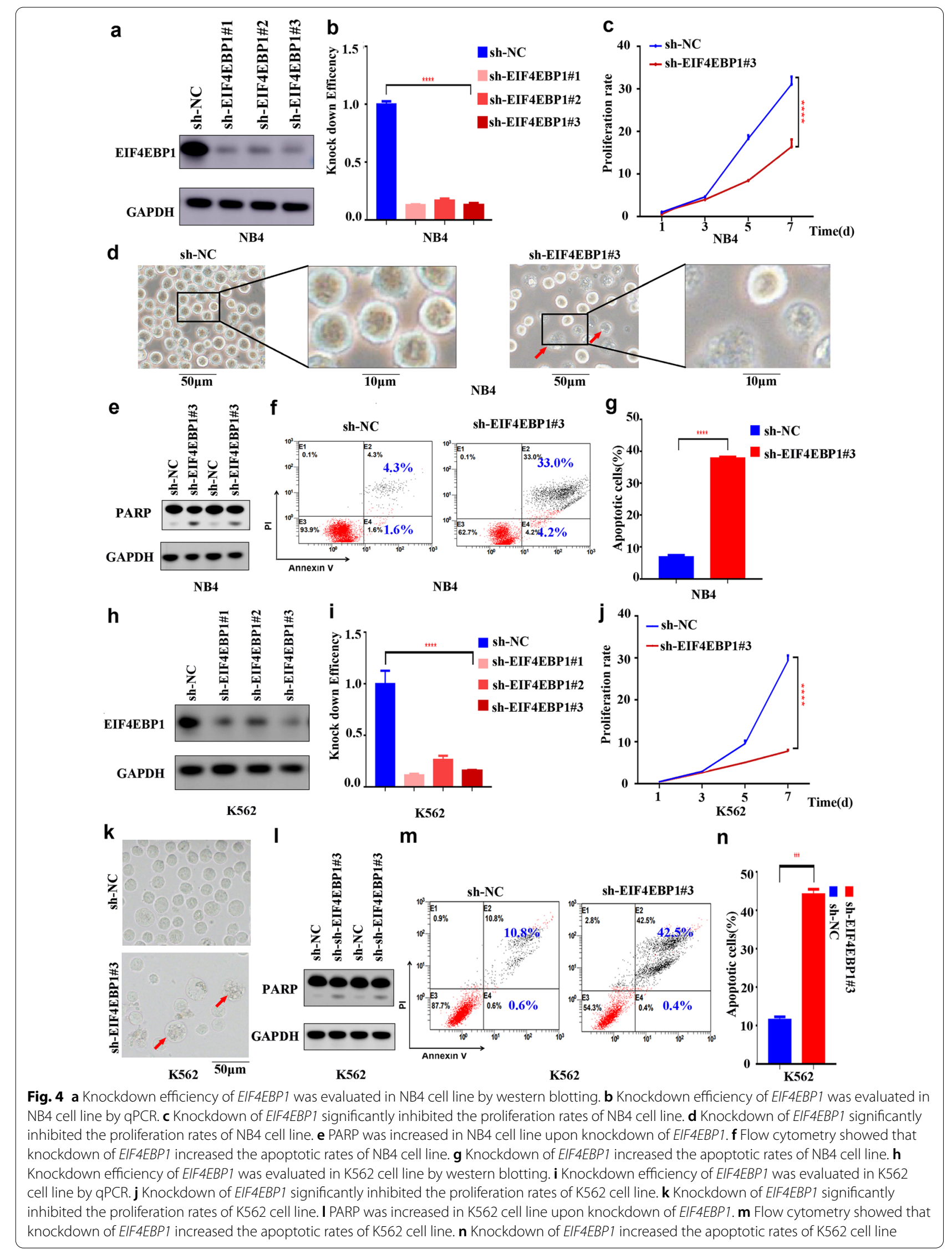



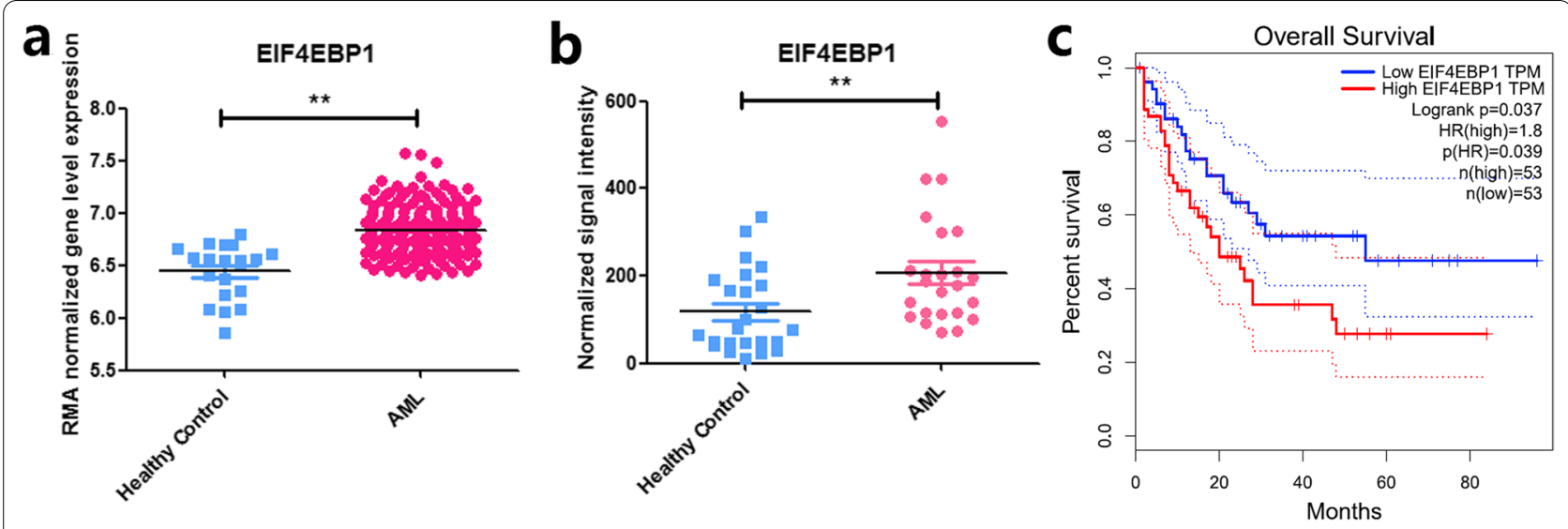

Fig. 5 a EIF4EBP1 was significantly overexpressed in AML samples in public transcriptomic dataset GSE1 14868. b EIF4EBP1 was significantly overexpressed in AML samples in public transcriptomic dataset GSE142700. c Base on the online tool http://gepia.cancer-pku.cn/, the overall survival of AML patients with higher EIF4EBP1 expression was significantly poorer than those with lower EIF4EBP1 expression

transcription factor family, has been implicated in multiple cancers [25-28]. For example, it is reported that CEBPG significantly promotes the proliferation and migration of esophageal squamous cell carcinoma (ESCC) cells, and is thus suggested as a prognostic factor for patients with ESCC [21].

Although a role for CEBPG in myeloid differentiation has been demonstrated [27, 28], if and how it contributes to the pathogenesis of AML is unclear. Here, we explored the function of CEBPG in AML and found that CEBPG is upregulated in AML and contributes to the proliferation of AML cells. We also demonstrated that CEBPG promotes AML cell proliferation by activating EIF4EBP1 in AML cell lines.

Eukaryotic translation initiation factor $4 \mathrm{E}$ binding protein 1 (EIF4EBP1) gene encodes a translation repressor protein [29]. This protein plays a role in multiple cancer types, including lung, breast, and liver cancer [30-33]. For example, EIF4EBP1 is reported to be significantly overexpressed in hepatocellular carcinoma (HCC) tissues and is related to poor survival of HCC patients [33]. However, the biological effect and underlying mechanism of EIF4EBP1 in AML has not been explored. In this study, we found the knockdown of EIF4EBP1 significantly inhibited proliferation and increases apoptosis in NB4 and K562 cells. Furthermore, in two public transcriptomic datasets (GSE114868 and GSE142700) [37], EIF4EBP1 was observed to be significantly overexpressed in AML samples. EIF4EBP1 was also identified as an unfavorable prognostic factor for AML patients using the online tool http://gepia.cancer-pku.cn/. Taken together, these results suggested that EIF4EBP1 is involved in the pathogenesis of AML and represents a negative prognostic factor for AML patients.
In summary, we explored the function of CEBPG in AML and identified CEBPG as a potential therapeutic target for AML patients. Our findings provide novel insights into the pathophysiology of AML and elucidated a crucial role of CEBPG in promoting AML progression.

\section{Abbreviations}

AML: Acute myeloid leukemia; ChIP: Chromatin immunoprecipitation; CEBPG: CCAAT enhancer binding protein gamma; EIF4EBP1: Eukaryotic translation initiation factor 4 E binding protein 1 .

\section{Supplementary Information}

The online version contains supplementary material available at https://doi. org/10.1186/s12935-021-02305-z.

Additional file 1: Table S1. Differentially expressed genes between AML and control samples in dataset GSE114868.

\section{Acknowledgements}

We would like to thank the department of Hematology, Children's Hospital of Soochow University, for the support in this study.

\section{Authors' contributions}

FF, JL, S-YH and JP designed and directed the study; YJ, S-YW, Y-LC, Z-MZ performed most of the experiments, analyzed the data, and wrote the paper; Y-FT, YX and X-ML helped with statistical analysis; H-RW, RZ and H-BC performed part of the experiments; J-JP, J-JY, S-QJ, ZZ, X-RC performed lentivirus preparation and transfection; $Y-P Z$, and J-WW participated in western blotting, $P C R$, and in vitro experiments; $C-x F$ and FF collected clinical data; $Y X$ and $X-L L$ supported the design of primers for real-time PCR; CF, XC and $Y Z$ helped with the apoptosis and cell cycle analysis; Z-HL, DW and GL participated in plasmid construction. All authors read and approved the final manuscript.

\section{Funding}

This work was supported by grants from the National Natural Science Foundation (81971867, 81802499, 81872845, 81902534, 82072767, 52003183); Natural Science Foundation of Jiangsu Province (BK20180206, BK20180207, SBK2019021442, BK20190185, BK20190186, BK20191175); the Universities Natural Science Foundation of Jiangsu Province (No.16KJB310014); Jiangsu 
province's science and technology support program (Social Development) project (BE2021657); Department of Pediatrics Clinical Center of Suzhou (Szzx201504); Gusu Health Talents program of Soochow city (2020-104); the Applied Foundational Research of Medical and Health Care of Suzhou City (SYS2018075, SYS2018074, SYS2019080, SYS2019082, SYS2019078, SYS2020150, SYS2020151); The Science and Technology Project of Soochow(SS201709).

\section{Availability of data and materials}

The data used and/or analyzed during the current study are available from the corresponding author on reasonable request (GSE178287).

\section{Declarations}

\section{Ethics approval and consent to participate}

This article does not contain any studies with human participants or animals performed by any of the authors.

\section{Consent for publication}

The consents for publication from all authors were obtained.

\section{Competing interests}

The authors declare that they have no conflicts of interest.

\section{Author details}

'Department of Hematology, Children's Hospital of Soochow University, No.92 Zhongnan Street, SIP, Suzhou 215003, Jiangsu, China. ${ }^{2}$ Intensive Care Unit, Children's Hospital of Soochow University, Suzhou 215003, China. ${ }^{3}$ Institute of Pediatric Research, Children's Hospital of Soochow University, No.92 Zhongnan Street, SIP, Suzhou 215003, China. ${ }^{4}$ School of Basic Medicine and Biological Sciences, Soochow University, Suzhou 215003, China.

Received: 27 July 2021 Accepted: 27 October 2021

Published online: 07 November 2021

\section{References}

1. Dohner H, Weisdorf DJ, Bloomfield CD. Acute myeloid leukemia. N Engl J Med. 2015;373(12):1136-52.

2. Récher C. Clinical Implications of Inflammation in Acute Myeloid Leukemia. Front Oncol. 2021;11:623952. https://doi.org/10.3389/fonc.2021. 623952 (eCollection 2021)

3. Pasquer $\mathrm{H}$, Tostain M, Kaci N, Roux B, Benajiba L. Descriptive and functional genomics in acute myeloid leukemia (AML): paving the road for a cure. Cancers (Basel). 2021;13(4):748. https://doi.org/10.3390/cancers130 40748.

4. Visser O, Trama A, Maynadié M, Stiller C, Marcos-Gragera R, De Angelis R, Mallone S, Tereanu C, Allemani C, Ricardi U, Schouten HC, RARECARE Working Group. Incidence, survival and prevalence of myeloid malignancies in Europe. Eur J Cancer. 2012;48(17):3257-66. https://doi.org/10. 1016/j.ejca.2012.05.024.

5. Kantarjian $\mathrm{H}$. Acute myeloid leukemia-major progress over four decades and glimpses into the future. Am J Hematol. 2016;91:131-45.

6. Short NJ, Rytting ME, Cortes JE. Acute myeloid leukaemia. Lancet. 2018;392:593-606.

7. Kadia TM, Ravandi F, Cortes J, Kantarjian H. Toward individualized therapy in acute myeloid leukemia: a contemporary review. JAMA Oncol. 2015;1:820-8

8. Doucette K, Karp J, Lai C. Advances in therapeutic options for newly diagnosed, high-risk AML patients. Ther Adv Hematol. 2021;12:20406207211001136. https://doi.org/10.1177/204062072110011 38 (eCollection 2021).

9. Konstandin NP, Pastore F, Herold T, Dufour A, Rothenberg-Thurley M, Hinrichsen T, Ksienzyk B, Tschuri S, Schneider S, Hoster E, Berdel WE, Woermann BJ, Sauerland MC, Braess J, Bohlander SK, Klein HG, Hiddemann W Metzeler KH, Spiekermann K. Genetic heterogeneity of cytogenetically normal AML with mutations of CEBPA. Blood Adv. 2018:2(20):2724-31. https://doi.org/10.1182/bloodadvances.2018016840.
10. Zhao X, Reebye V, Hitchen P, Fan J, Jiang H, Sætrom P, Rossi J, Habib NA, Huang KW. Mechanisms involved in the activation of C/EBPa by small activating RNA in hepatocellular carcinoma. Oncogene. 2019;38:3446-57.

11. Akasaka T, Balasas T, Russell LJ, Sugimoto KJ, Majid A, Walewska R, Karran EL, Brown DG, Cain K, Harder L, Gesk S, Martin-Subero J, Atherton MG, Brüggemann M, Calasanz MJ, Davies T, Haas OA, Hagemeijer A, Kempski H, Lessard M, Lillington DM, Moore S, Nguyen-Khac F, Radford-Weiss I, Schoch C, Struski S, Talley P, Welham MJ, Worley H, Strefford JC, Harrison CJ, Siebert R, Dyer MJ. Five members of the CEBP transcription factor family are targeted by recurrent IGH translocations in B-cell precursor acute lymphoblastic leukemia (BCP-ALL). Blood. 2007;109:3451-61.

12. Avellino R, Havermans M, Erpelinck C, Sanders MA, Hoogenboezem R, van de Werken HJ, Rombouts E, van Lom K, van Strien PM, Gebhard C, Rehli M, Pimanda J, Beck D, Erkeland S, Kuiken T, de Looper H, Gröschel S, Touw I, Bindels E, Delwel R. An autonomous CEBPA enhancer specific for myeloid-lineage priming and neutrophilic differentiation. Blood. 2016;127:2991-3003.

13. Shyamsunder P, Shanmugasundaram M, Mayakonda A, Dakle P, Teoh WW, Han L, Kanojia D, Lim MC, Fullwood M, An O, Yang H, Shi J, Hossain MZ, Madan V, Koeffler HP. Identification of a novel enhancer of CEBPE essential for granulocytic differentiation. Blood. 2019;133:2507-17.

14. Lourenço AR, Coffer PJ. A tumor suppressor role for C/EBPa in solid tumors: more than fat and blood. Oncogene. 2017;36:5221-30.

15. Wu H, Liu B, Chen Z, Li G, Zhang Z. MSC-induced InCRNA HCP5 drove fatty acid oxidation through miR-3619-5p/AMPK/PGC1alpha/CEBPB axis to promote stemness and chemo-resistance of gastric cancer. Cell Death Dis. 2020;11(4):233. https://doi.org/10.1038/s41419-020-2426-z.

16. Wang F, Gao Y, Tang L, Ning K, Geng N, Zhang H, Li Y, Li Y, Liu F, Li F. A novel PAK4-CEBPB-CLDN4 axis involving in breast cancer cell migration and invasion. Biochem Biophys Res Commun. 2019;511(2):404-8. https:// doi.org/10.1016/j.bbrc.2019.02.070.

17. Sun $X$, Jefferson P, Zhou Q, Angelastro JM, Greene LA. Dominant-negative ATF5 compromises cancer cell survival by targeting CEBPB and CEBPD. Mol Cancer Res. 2020;18(2):216-28. https://doi.org/10.1158/1541-7786. MCR-19-0631.

18. Yang Y, Xia S, Zhang L, Wang W, Chen L, Zhan W. MiR-324-5p/PTPRD/ CEBPD axis promotes papillary thyroid carcinoma progression via microenvironment alteration. Cancer Biol Ther. 2020;21(6):522-32. https://doi. org/10.1080/15384047.2020.1736465.

19. Li K, Du Y, Wei DQ, Zhang F. CEBPE expression is an independent prognostic factor for acute myeloid leukemia. J Transl Med. 2019;17(1):188. https://doi.org/10.1186/s12967-019-1944-x.

20. Herold T, Metzeler KH, Vosberg S, Hartmann L, Röllig C, Stölzel F, Schneider S, Hubmann M, Zellmeier E, Ksienzyk B, Jurinovic V, Pasalic Z, Kakadia PM, Dufour A, Graf A, Krebs S, Blum H, Sauerland MC, Büchner T, Berdel WE, Woermann BJ, Bornhäuser M, Ehninger G, Mansmann U, Hiddemann W, Bohlander SK, Spiekermann K, Greif PA. Isolated trisomy 13 defines a homogeneous AML subgroup with high frequency of mutations in spliceosome genes and poor prognosis. Blood. 2014;124(8):1304-11. https:// doi.org/10.1182/blood-2013-12-540716.

21. Huang Y, Lin L, Shen Z, Li Y, Cao H, Peng L, Qiu Y, Cheng X, Meng M, Lu D, Yin D. CEBPG promotes esophageal squamous cell carcinoma progression by enhancing PI3K-AKT signaling. Am J Cancer Res. 2020;10(10):3328-44 (eCollection 2020).

22. Tsukada J, Yoshida Y, Kominato Y, Auron PE. The CCAAT/enhancer (C/EBP) family of basic-leucine zipper (bZIP) transcription factors is a multifaceted highly-regulated system for gene regulation. Cytokine. 2011;54:6-19.

23. Fong Y, Shen $\mathrm{KH}$, Chen $L J$, Cheng JT. Changes of CCAAT enhancer-binding proteins (CEBPs) in the lung of streptozotocin-induced diabetic rats. Horm Metab Res. 2011;43:261-7.

24. Yang J, Croniger CM, Lekstrom-Himes J, Zhang P, Fenyus M, Tenen DG, Darlington GJ, Hanson RW. Metabolic response of mice to a postnatal ablation of CCAAT/enhancer-binding protein alpha. J Biol Chem. 2005:280:38689-99.

25. Atkins M, Potier D, Romanelli L, Jacobs J, Mach J, Hamaratoglu F, Aerts S, Halder G. An ectopic network of transcription factors regulated by hippo signaling drives growth and invasion of a malignant tumor model. Curr Biol. 2016;26(16):2101-13. https://doi.org/10.1016/j.cub.2016.06.035.

26. Blomquist T, Crawford EL, Mullins D, Yoon Y, Hernandez DA, Khuder S, Ruppel PL, Peters E, Oldfield DJ, Austermiller B, Anders JC, Willey JC. Pattern of antioxidant and DNA repair gene expression in normal 
airway epithelium associated with lung cancer diagnosis. Cancer Res. 2009;69(22):8629-35. https://doi.org/10.1158/0008-5472.CAN-09-1568.

27. Brown AL, de Smith AJ, Gant VU, Yang W, Scheurer ME, Walsh KM, Chernus JM, Kallsen NA, Peyton SA, Davies GE, Ehli EA, Winick N, Heerema NA, Carroll AJ, Borowitz MJ, Wood BL, Carroll WL, Raetz EA, Feingold E, Devidas M, Barcellos LF, Hansen HM, Morimoto L, Kang AY, Smirnov I, Healy J, Laverdière C, Sinnett D, Taub JW, Birch JM, Thompson P, Spector LG, Pombode-Oliveira MS, DeWan AT, Mullighan CG, Hunger SP, Pui CH, Loh ML, Zwick ME, Metayer C, Ma X, Mueller BA, Sherman SL, Wiemels JL, Relling MV, Yang JJ, Lupo PJ, Rabin KR. Inherited genetic susceptibility to acute lymphoblastic leukemia in down syndrome. Blood. 2019;134:1227-37.

28. Alberich-Jordà M, Wouters B, Balastik M, Shapiro-Koss C, Zhang H, Di Ruscio A, Radomska HS, Ebralidze AK, Amabile G, Ye M, Zhang J, Lowers I, Avellino R, Melnick A, Figueroa ME, Valk PJ, Delwel R, Tenen DG. C/EBPY deregulation results in differentiation arrest in acute myeloid leukemia. J Clin Invest. 2012;122:4490-504.

29. Wang H, Ma X, Liu J, Wan Y, Jiang Y, Xia Y, Cheng W. Prognostic value of an autophagy-related gene expression signature for endometrial cancer patients. Cancer Cell Int. 2020;20:306. https://doi.org/10.1186/s12935020-01413-6.eCollection2020.

30. Li SQ, Feng J, Yang M, Ai XP, He M, Liu F. Sauchinone: a prospective therapeutic agent-mediated EIF4EBP1 down-regulation suppresses proliferation, invasion and migration of lung adenocarcinoma cells. J Nat Med. 2020;74(4):777-87. https://doi.org/10.1007/s11418-020-01435-4.

31. Qin X, Jiang B, Zhang Y. 4E-BP1, a multifactor regulated multifunctional protein. Cell Cycle. 2016;15(6):781-6.
32. Wan B, Liu B, Yu G, Huang Y, Lv C. Differentially expressed autophagyrelated genes are potential prognostic and diagnostic biomarkers in clear-cell renal cell carcinoma. Aging (Albany NY). 2019;11(20):9025-42. https://doi.org/10.18632/aging.102368.

33. Cha YL, Li PD, Yuan LJ, Zhang MY, Zhang YJ, Rao HL, Zhang HZ, Zheng XF, Wang HY. EIF4EBP1 overexpression is associated with poor survival and disease progression in patients with hepatocellular carcinoma. PLoS ONE. 2015;10:e0117493.

34. Langmead B, Salzberg S. Fast gapped-read alignment with Bowtie 2. Nat Methods. 2012;9:357-9.

35. Zhang Y, Liu T, Meyer CA, Eeckhoute J, Johnson DS, Bernstein BE, et al. Model-based analysis of ChIP-Seq (MACS). Genome Biol. 2008;9:R137.

36. Robinson JT, Thorvaldsdóttir H, Winckler W, Guttman M, Lander ES, Getz G, Mesirov JP. Integrative genomics viewer. Nat Biotechnol. 2011;29(1):24-6.

37. Huang HH, Chen FY, Chou WC, Hou HA, Ko BS, Lin CT, Tang JL, Li CC, Yao M, Tsay W, Hsu SC, Wu SJ, Chen CY, Huang SY, Tseng MH, Tien HF, Chen RH. Long non-coding RNA HOXB-AS3 promotes myeloid cell proliferation and its higher expression is an adverse prognostic marker in patients with acute myeloid leukemia and myelodysplastic syndrome. BMC Cancer. 2019;19(1):617. https://doi.org/10.1186/s12885-019-5822-y.

\section{Publisher's Note}

Springer Nature remains neutral with regard to jurisdictional claims in published maps and institutional affiliations.
Ready to submit your research? Choose BMC and benefit from:

- fast, convenient online submission

- thorough peer review by experienced researchers in your field

- rapid publication on acceptance

- support for research data, including large and complex data types

- gold Open Access which fosters wider collaboration and increased citations

- maximum visibility for your research: over 100M website views per year

At BMC, research is always in progress.

Learn more biomedcentral.com/submissions 